\title{
ErbB2-enhanced invasiveness of H-Ras MCF10A breast cells requires MMP-13 and uPA upregulation via p38 MAPK signaling
}

\author{
HAE-YOUNG YONG ${ }^{1}$, IN-YOUNG KIM ${ }^{2}$, JONG SUK KIM ${ }^{1}$ and AREE MOON ${ }^{1}$ \\ ${ }^{1}$ College of Pharmacy, Duksung Women's University, Seoul 132-714, Korea
}

Received September 24, 2009; Accepted October 28, 2009

DOI: 10.3892/ijo_00000524

\begin{abstract}
Overexpression of ErbB2 has been frequently found in mammary carcinoma. We have previously shown that the aberrant activation of $\mathrm{H}$-Ras induces human breast cell invasion and migration. The present study was aimed at investigating the effect of ErbB2 overexpression on H-Ras-induced breast cell invasion and to elucidate the underlying mechanisms. Herein, we show that overexpression of ErbB2 promotes invasive and migratory abilities of H-Ras-activated MCF10A human breast epithelial cells through upregulation of matrix metalloproteinase (MMP)-13 and urokinase-type plasminogen activator (uPA). We also demonstrate that the p38 MAPK is an important signaling molecule in the ErbB2-induced upregulation of MMP-13 and UPA and invasion/migration of H-Ras MCF10A cells overexpressing ErbB2. The present study elucidating the molecular mechanism underlying ErbB2-induced promotion of H-Ras MCF10A cell invasion may provide invaluable information for understanding breast cancer progression and establishing therapeutic interventions for breast cancer.
\end{abstract}

\section{Introduction}

The metastatic spread of the disease is the major cause of death from breast cancer. Since genetic alterations can contribute to the progression and metastasis of breast cancer, studies on the molecular mechanisms involved in breast cancer invasion are important for the identification of genes that augment the metastatic or invasive potential of breast cancer cells. ErbB2 (also known as HER-2/neu) is the oncogenic receptor tyrosine kinase which has extensive sequence homology to epidermal growth factor receptor $(1,2)$. ErbB2

Correspondence to: Dr Aree Moon, College of Pharmacy, Duksung Women's University, Seoul 132-714, Korea

E-mail: armoon@duksung.ac.kr

Present address: ${ }^{2}$ Korea Food and Drug Administration, Busan, Korea

Key words: ErbB2, matrix metalloproteinase-13, urokinase-type plasminogen activator, p38 MAPK, breast cancer signaling can promote malignant transformation, in part, by Ras activation $(3,4)$. Extracellular stimuli that act on ErbB2 cause transient activation of Ras which in turn activates multiple downstream effectors that stimulate cytoplasmic signaling cascades that regulate a variety of malignant processes including cell proliferation, invasion and migration (5-7). Amplification or overexpression of ErbB2 has been found in $20-30 \%$ of human breast cancers (8). Mounting evidence indicates that overexpression of ErbB2 plays an important role in human breast cancer metastasis (9-13).

Invasive and metastatic processes of malignant tumor require the expression and activation of matrix metalloproteinases (MMPs) which induce the progression of tumor cells including degradation of the extracellular matrix and basement membrane (14). Human MMP gene family contains more than 20 members $(15,16)$. Expressions of MMP-2 and MMP-9 have been shown to be associated with the progression of metastasis $(17,18)$. MMP-13 is expressed in breast carcinomas and head and neck squamous cell carcinomas and its expression correlates with invasion of these carcinomas $(19,20)$. Urokinase-type plasminogen activator (uPA) represents a second extracellular proteolytic system which is known to play a critical role in tumor invasion and metastasis $(21,22)$. Co-expression of MMPs and uPA was observed during tumor invasion and metastasis (23-25). ErbB2 activation induces the transcriptional activation of $\mathrm{uPA}$ and MMPs $(26,27)$ and regulates expression and activity of these proteases in breast cancer cell lines and breast cancer patients (9,28-31). We have previously shown that ErbB2 induces invasive and migratory phenotypes for which MMP-9 is responsible in MCF10A human breast epithelial cells (32).

Mutations of the ras gene are among the most frequent genetic alterations in human tumors (33). Although ras mutations are rarely seen in breast cancers, aberrant Ras activation may promote breast cancer development $(34,35)$. The single point mutation at amino acid residue 12 (Gly to Asp) of H-Ras is often found in mammary carcinoma (36). Using MCF10A cell system in which H-Ras is constitutively activated, we showed that $\mathrm{H}$-Ras activation induced invasive and migratory phenotypes (37). We also showed that upregulation of MMP-2 was crucial to the H-Ras-induced phenotypic changes $(38,39)$.

In order to determine the effect of ErbB2 overexpression on H-Ras-induced breast cell invasion and the underlying mechanisms, we investigated the invasiveness of H-Ras 
MCF10A cells overexpressing ErbB2 and the involvement of various proteases. Herein we report that ErbB2 enhances invasion and migration of H-Ras MCF10A cells through MMP-13 and uPA. We further show that p38 MAPK signaling pathway plays a critical role in the ErbB2-enhanced invasiveness and upregulation of MMP-13 and uPA in H-Ras-activated human breast cells.

\section{Materials and methods}

Cell lines. Development and characterization of H-Ras MCF10A cells have been described previously (37). The H-Ras MCF10A cell line overexpressing ErbB2 (ErbB2-HRas MCF10A cell line), which was kindly provided by Dr K.W. Kang (Chosun University, Gwang-Ju, Korea), was established using an MSCV-GFP retrovirus system as previously described (40). Cells were cultured in DMEM/ F12 medium supplemented with $5 \%$ horse serum, $0.5 \mu \mathrm{g} / \mathrm{ml}$ hydrocortisone, $10 \mu \mathrm{g} / \mathrm{ml}$ insulin, $20 \mathrm{ng} / \mathrm{ml}$ epidermal growth factor, $0.1 \mu \mathrm{g} / \mathrm{ml}$ cholera enterotoxin, $100 \mathrm{U} / \mathrm{ml}$ penicillinstreptomycin, $2 \mathrm{mM}$ L-glutamine and $0.5 \mu \mathrm{g} / \mathrm{ml}$ amphotericin $\mathrm{B}$.

In vitro invasion assay. In vitro invasion assay was performed using a 24-well transwell unit with polycarbonate filters (Corning Costar, Cambridge, MA) as previously described (38). Cells were placed in the upper part of the transwell plate, incubated for $18 \mathrm{~h}$, fixed with methanol and stained with hematoxylin for $10 \mathrm{~min}$ followed briefly by eosin. The invasive phenotypes were determined by counting the cells that migrated to the lower side of the filter with microscopy at $x 400$. Thirteen fields were counted for each filter and each sample was assayed in triplicate.

In vitro migration assay using transwell. In vitro migration assay was performed using a 24-well transwell unit with polycarbonate filters as previously described (38). Experimental procedures are the same as the in vitro invasion assay described above except that the filter was not coated with Matrigel for the migration assay.

Western blot analysis. Western blot analysis was performed as previously described (38). Briefly, equal amounts of protein extracts in SDS-lysis buffer were subjected to $12 \%$ SDSPAGE analysis and electrophoretically transferred to nitrocellulose membrane. Anti-MMP-2, anti-MMP-13 and antiuPA antibodies were purchased from R\&D Systems, Inc. (Minneapolis, MN, USA). Anti-MMP-9 antibody was purchased from Santa Cruz Biotechnology, Inc. (Santa Cruz, CA, USA). Anti-MEK, anti-phosphorylated MEK, anti-ERK, anti-phosphorylated ERK, anti-p38, anti-phosphorylated p38, anti-Akt, anti-phosphorylated Akt, and anti-phosphorylated Raf1 antibodies were purchased from Cell Signaling Technology, Inc. (Beverly, MA, USA). Anti-Rac1 and anti-phosphotyrosine antibodies were purchased from Upstate Biotechnology, Inc. (Lake Placid, NY, USA). Enhanced chemiluminescence (ECL, Amersham-Pharmacia, Buckinghamshire, UK) system was used for detection. Relative band intensities were determined by quantitation of each band with an Image Analyzer (Vilber Lourmet, France).
Knockdown of MMP-13 and UPA by small-interfering (si) RNA. An siRNA targeting MMP-13 (5'-AUUUCUCGGAG CCUCUCAGUCAUGG-3') and an siRNA targeting uPA (5'-UAAUUCUUCUGGAGGAGAGGAGGGC-3') were purchased from Invitrogen (Carlsbad, CA, USA). Cells in the exponential phase of growth were plated in six-well plates at $2 \times 10^{5}$ cells/well, grown for $24 \mathrm{~h}$ then transfected with 100 pmol siRNA for $6 \mathrm{~h}$ using Lipofectamine 2000 reagent and OPTI-MEMI reduced serum medium (Invitrogen). Control cells were transfected with Stealth ${ }^{\mathrm{TM}}$ RNAi negative control duplex (Invitrogen).

Racl activity assay. The levels of Rac1-GTP were measured by affinity precipitation using PAK-1 PBD Rac assay reagent (Upstate Biotech. Inc., Lake Placid, NY) following manufacturer's instruction as previously described $(41,50)$. Proteins were separated by $12 \%$ SDS-PAGE, transferred to nitrocellulose membrane, and blotted with anti-Rac1 antibody.

Raf-1 activity assay. The Raf-1 activity was measured as previously described (50). Briefly, cell lysates were preincubated with protein A-sepharose suspension (Roche, Basel, Switzerland). The supernatant was incubated with anti-Raf-1 antibody. Protein A-sepharose suspension was added and incubation was extended overnight on ice with shaking. The antibody-antigen complex was washed twice in lysis buffer and twice in high salt buffer and then the SDS-PAGE loading buffer was added. Immunoblot analysis was performed to assess the activity of immunoprecipitated Raf-1 with antiphosphorylated Raf-1 antibody.

Reverse transcription (RT)-PCR. RNA was reverse transcribed with RT-Superscript III reverse transcriptase (Invitrogen). MMP-1, MMP-2, MMP-3, MMP-7, MMP-8 MMP-9, MMP-13 and uPA were synthesized by RT-PCR using the following primers: MMP-1: sense 5'-GGAGGG GATGCTCATTTTGATG-3' antisense 5'-TAGGGAAGC CAAAGGAGCTGT-3', MMP-2: sense 5'-AATGCCATC CCCGATAACC-3' antisense 5'-AAACTTCACGCTCTTCA GAC-3', MMP-3: sense 5'-CCTGCTTTGTCCTTTGATGC-3' antisense 5'-GAGTCAATCCCTGGAAAGTC-3', MMP-7: sense 5'-ATGTTAAACTCCCGCGTCATA-3' antisense 5'-C AGCATACAGGAAGTTAATCC-3', MMP-8: sense 5'-TGG ACCCAATGGAATCCTTGC-3' antisense 5'-ATAGCC ACTCAGAGCCCAGTA-3', MMP-9: sense 5'-TCTTCC AGTACCGAGAGAAAG-3' antisense 5'-AGGATGTCA TAGGTCACGTAG-3', MMP-13: sense 5'-TTGTTGCTG CGCATGAGTTCG-3' antisense 5'-GGGTGCTCATAT GCAGCATCA-3', uPA: sense 5'-CACGCAAGGGGAGAT GAA-3' antisense 5'-ACAGCATTTTGGTGGTGACTT-3'. Thermocycler conditions were as previously described (42).

\section{Results}

ErbB2 overexpression enhances invasive and migratory abilities of H-Ras MCF10A cells. To investigate the effect of ErbB2 on the invasion and migration of H-Ras-activated MCF10A cells, ErbB2 gene was introduced into H-Ras MCF10A cells by transfection, resulting a stable cell line ErbB2-H-Ras MCF10A. The intrinsic level of ErbB2 
A

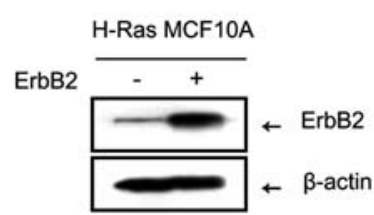

B

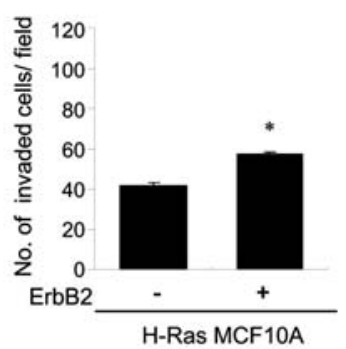

A

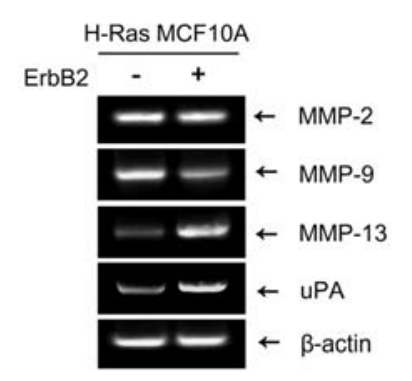

C

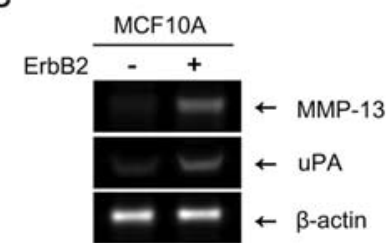

B

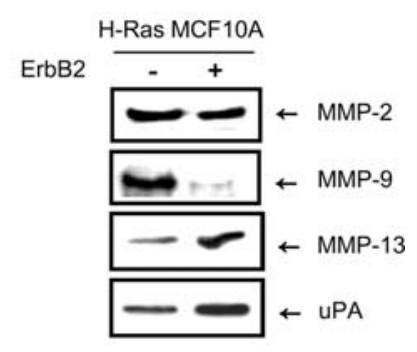

Figure 1. ErbB2 induces invasion and migration of H-Ras MCF10A cells. (A) Cell lysates were collected and the expression of ErbB2 was detected by Western blot analysis. B-actin was used as a loading control. (B) Cells were subjected to the in vitro invasion assay and transwell migration assay. The number of invaded or migrated cells per field was counted (x400) in 13 arbitrary visual fields. The results represent means \pm SE of triplicates. ${ }^{*},{ }^{* *}$ Statistically different from control at $\mathrm{p}<0.05$ and $\mathrm{p}<0.01$, respectively, by the two-tailed Student's t-test.

A

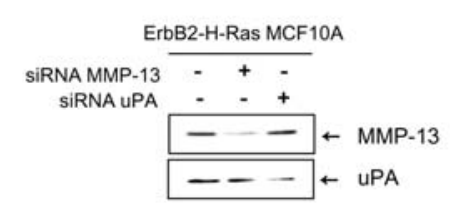

B

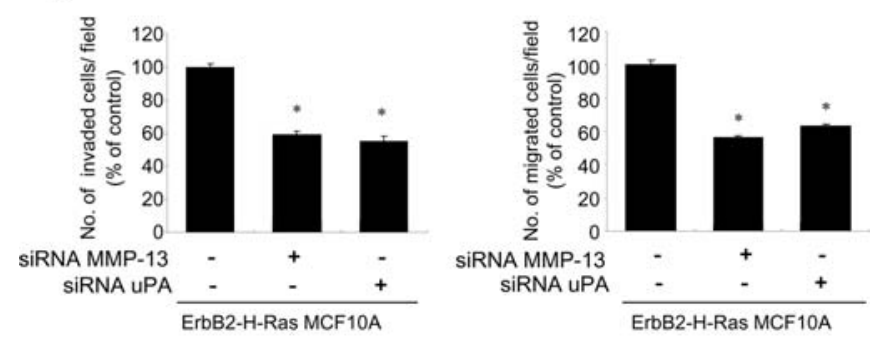

Figure 3. MMP-13 and uPA are essential to the invasion and migration of ErbB2-H-Ras MCF10A cells. (A) Knockdown of MMP-13 or uPA by siRNA was confirmed by Western blot analysis. Control cells were treated with Stealth RNAi negative control duplexes. (B) Cells transfected with siRNA for MMP-13 and uPA were subjected to in vitro invasion assay (left panel) or transwell migration assay (right panel). The number of invaded or migrated cells per field was counted (x400) in 13 arbitrary visual fields. The results represent means \pm SE of triplicates. *Statistically different from control at $\mathrm{p}<0.01$.

expression was low in H-Ras MCF10A cells. Overexpression of ErbB2 in ErbB2-H-Ras MCF10A cells was confirmed by Western blot analysis (Fig. 1A). Overexpression of ErbB2 caused significant increases in invasiveness and migration of H-Ras MCF10A cells, demonstrating that ErbB2 enhanced invasive and migratory abilities of H-Ras MCF10A cells (Fig. 1B).

ErbB2 upregulates $M M P-13$ and $u P A$. Our previous report has shown that ErbB2 induces upregulation of MMP-9 in the parental MCF10A cells (32). The present study investigated the effect of ErbB2 on the expression of various proteases in H-Ras MCF10A cells by RT-PCR analysis. As shown in Fig. 2A, the expression of mRNAs of MMP-1, MMP-2, MMP-3, MMP-7, MMP-8, MMP-9, MMP-13 and uPA was observed in H-Ras MCF10A and ErbB2-H-Ras MCF10A cells. The mRNAs of MMP-1, MMP-3, MMP-7 and MMP-8 were detected neither in H-Ras MCF10A cells nor in the ErbB2-HRas MCF10A cells (data not shown). The levels of MMP-2 and MMP-9 were strong in H-Ras MCF10A cells as previously reported (37) while the levels of MMP-13 and UPA were weak in these cells. The mRNA levels of MMP-13 and uPA were markedly increased by ErbB2 overexpression. The mRNA level of MMP-2 was not altered and the MMP-9 mRNA level was decreased in ErbB2-H-Ras MCF10A cells. The data from RT-PCR were confirmed by Western blot analysis (Fig. 2B), clearly demonstrating that among the proteases tested, MMP-13 and UPA were upregulated by ErbB2 overexpression in H-Ras MCF10A cells. We then asked whether ErbB2 upregulated MMP-13 and uPA in the parental MCF10A cells. As shown in Fig. 2C, the mRNA levels of MMP-13 and uPA were increased by ErbB2 in MCF10A cells. These results suggest that MMP-13 and uPA may be involved in the ErbB2-enhanced invasive and migratory phenotypes in human breast epithelial cells.

MMP-13 and UPA are critical to the ErbB2-enhanced invasion and migration. In order to determine the functional significance of MMP-13 and UPA in the invasion and migration of ErbB2-H-Ras MCF10A cells, we selectively knocked down the expression of MMP-13 or uPA using an siRNA approach. Inhibition of MMP-13 or uPA by siRNA 

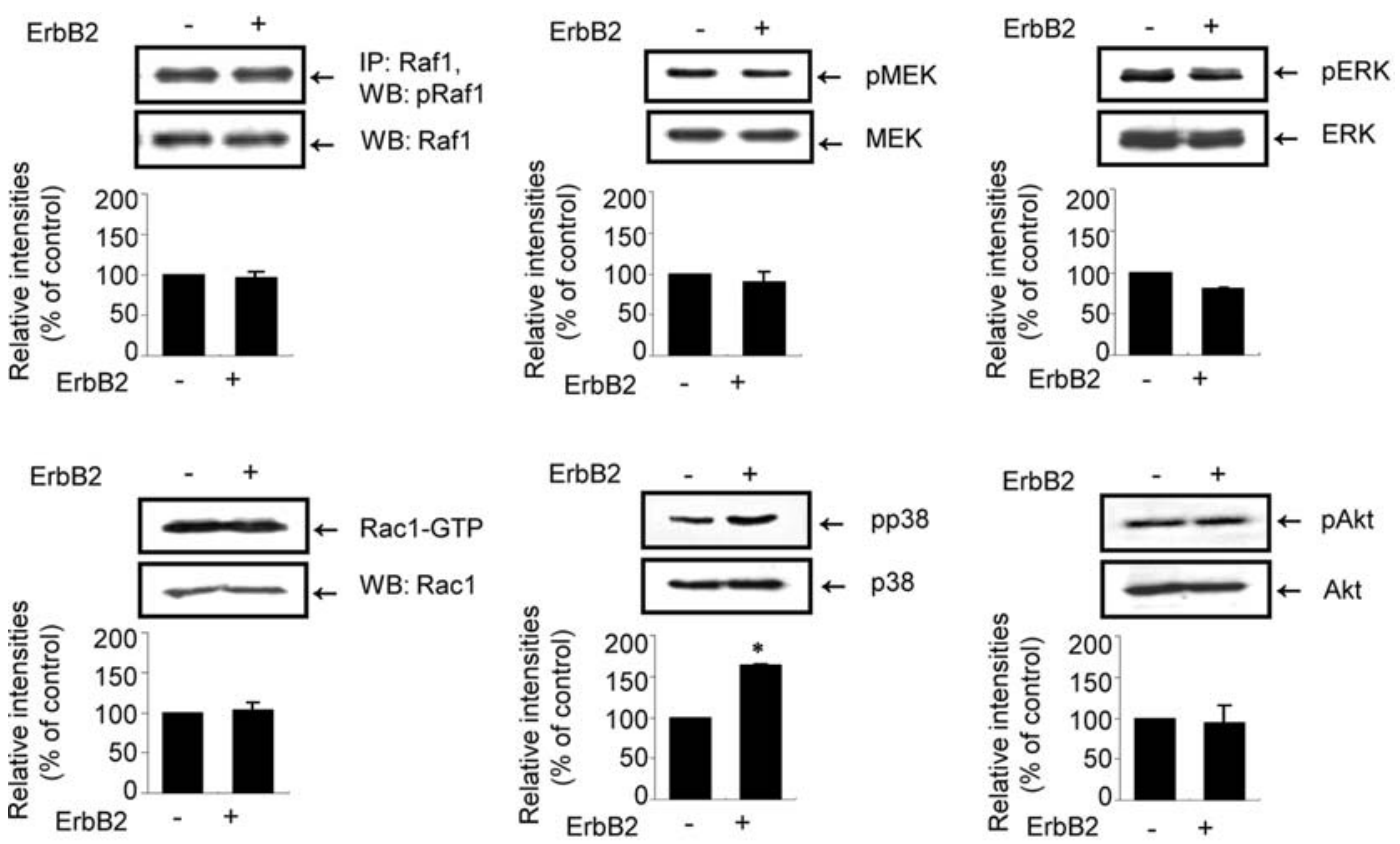

Figure 4. ErbB2 activates p38 MAPK in H-Ras MCF10A cells. The levels of activated MEK, ERK, p38 MAPK and Akt in H-Ras MCF10A and ErbB2-H-Ras MCF10A cells were determined by Western blot analysis. The immunoblots shown are representative of three blots from independent experiments. For Raf-1 activity, immunoprecipitated (IP) with anti-Raf-1 antibody and probed with phosphorylated Raf-1 antibody. For Rac1 activity, cell lysates were incubated with GST-PBD fusion protein, and the bound active Rac1-GTP molecules were analyzed by immunoblotting using anti-Rac1 antibody. Relative band intensities from three independent blots were determined by using an image analyzer. "Statistically different from control at $\mathrm{p}<0.01$.

A
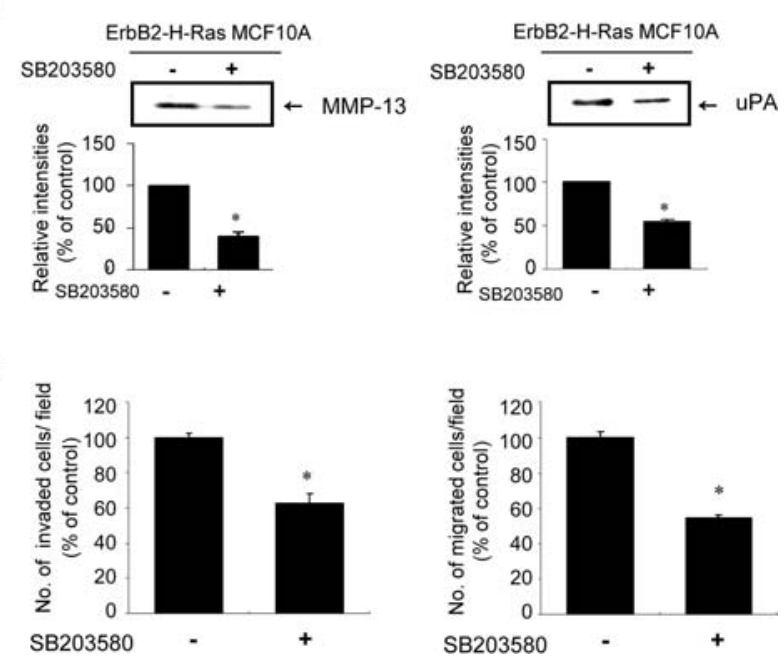

Figure 5. p38 MAPK plays an important role in ErbB2-induced MMP-13 and uPA upregulation, invasion and migration. (A) ErbB2-H-Ras MCF10A cells were treated with $50 \mu \mathrm{M}$ of SB203580 for $48 \mathrm{~h}$. Conditioned media were collected and the levels of secreted MMP-13 and uPA were determined by Western blot analysis. The immunoblots shown are representative of three blots from independent experiments. Relative band intensities from three independent blots were determined by using an image analyzer. *Statistically different from control at $\mathrm{p}<0.01$. (B) ErbB2-H-Ras MCF10A cells pretreated with $50 \mu \mathrm{M} \mathrm{SB} 203580$ for 30 min were subjected to in vitro invasion assay (left panel) and migration assay (right panel) in the presence of the compound. The number of invaded cells per field was counted $(x 400)$ in 13 fields. The results presented are means \pm SE of triplicates. "Statistically different from control at $\mathrm{p}<0.01$

molecules targeting these genes was proven by Western blot analysis (Fig. 3A). Following MMP-13 knock-down, invasiveness of ErbB2-H-Ras MCF10A cells was significantly inhibited by $41 \%$ as determined by in vitro invasion assay (Fig. 3B, left). A similar extent of inhibition in invasion (45\%) was observed when uPA expression was knocked-down. Similarly, ErbB2-H-Ras MCF10A cell motility was inhibited by knock-down of MMP-13 and uPA by 43.7 and $36.9 \%$, respectively (Fig. 3B, right). The results demonstrate that MMP-13 and uPA play critical roles in ErbB2-enhanced cell invasion and migration in H-Ras MCF10A cells.

ErbB2-induced MMP-13 and UPA upregulation is mediated by $p 38 M A P K$. In order to investigate the specific roles of signaling pathways in the upregulation of MMP-13 and uPA by ErbB2, we detected the activation of signaling molecules in ErbB2-H-Ras MCF10A cells. As shown in Fig. 4, the phosphorylation of p38 MAPK was increased by ErbB2, while the levels of active Raf1, phosphorylated MEK, ERK-1/2, Rac1, Akt were not affected. These results indicate that the p38 MAPK signaling pathway may be involved in the enhancing effect of ErbB2 on H-Ras MCF10A cell invasion and migration.

We then examined the functional role of p38 MAPK signaling in MMP-13 and uPA expressions and invasive/ migratory phenotypes of ErbB2-H-Ras MCF10A cells. Treatment with $50 \mu \mathrm{M}$ of SB203580, a pharmacological inhibitor of p38 MAPK, significantly inhibited the expression levels of MMP-13 and uPA (Fig. 5A), indicating that the activation of $\mathrm{p} 38$ MAPK is critical to the upregulation MMP-13 and uPA by ErbB2. Moreover, invasion and migration of ErbB2-MCF10A cells were significantly inhibited by treatment with $50 \mu \mathrm{M}$ of SB203580 by 37.3 and $45.7 \%$, 
respectively (Fig. 5B). These results demonstrate that p38 MAPK signaling pathway plays a critical role in the ErbB2mediated upregulation of MMP-13 and UPA as well as in the ErbB2-promoted invasive and migratory abilities of H-Ras MCF10A cells.

\section{Discussion}

Breast cancer is one of the most frequent malignancies in women and the major cause of death from breast cancer is the metastatic spread of the disease from the primary tumor to distant sites in the body. Since about $20-30 \%$ of human breast cancers show amplification or overexpression of ErbB2 (43) and overexpression of ErbB2 plays an important role in human breast cancer metastasis, this study aimed to investigate the effect of ErbB2 overexpression on H-Ras-induced breast cell invasion and to elucidate the underlying mechanisms. Recent studies demonstrate that there is a close association between ErbB2 and Ras activation $(7,44)$. ErbB2 overexpression is correlated with the increased Ras-GTP formation in breast tumor tissues and cell lines $(4,45)$. On the other hand, constitutively activated K-Ras and amplification of C-ErbB2 seem to occur independently in the process of colon tumor progression (46). Here, we show that invasive and migratory abilities of H-Ras MCF10A cells were significantly increased by ErbB2 overexpression, indicating the enhancing effect of ErbB2 on H-Ras-induced malignant phenotypic changes.

A linkage between ErbB2 activation and tumor progression was shown to be mediated by MMP family members. ErbB2 increases invasive capacities of malignant cancer cell lines by stimulating the expressions of uPA (47), uPAR (48), MMP-1 (26), MMP-2 (47), MMP-7 (47), MMP-9 (47) and MMP-13 (49). The present study demonstrates that ErbB2 overexpression increases the expressions of MMP-13 and uPA in H-Ras MCF10A cells (Fig. 2). Using siRNA knockdown approach, we revealed MMP-13 and uPA as important players in the ErbB2-induced invasion and migration of H-Ras MCF10A cells. In consistent with our results, overexpression of uPA in ErbB2-positive breast cancer tissues has been shown to determine the aggressive and metastatic clinical behaviors (31).

Activation of H-Ras induces expressions of MMP-2 and MMP-9 in MCF10A cells as shown in Fig. 2 and in our previous report (37). ErbB2 overexpression induces the expression of MMP-9 but not that of MMP-2 in these cells (32). Our results show that the H-Ras-induced MMP-2 expression was not affected by ErbB2 overexpression. Interestingly, the expression of MMP-9 in H-Ras-activated cells was significantly decreased by overexpression of ErbB2 (Fig. 2). These data indicate that the single activation of ErbB2 or H-Ras enhances MMP-9 expression while the co-expression of ErbB2 and H-Ras inhibits MMP-9 expression. The results suggest that crosstalk between ErbB2 and H-Ras signaling may suppress the expression of MMP-9.

Among signaling molecules tested, ErbB2 activates p38 MAPK in H-Ras MCF10A cells (Fig. 4). Functional significance of p38 MAPK signaling in invasive and migratory phenotypes was demonstrated in ErbB2-H-Ras MCF10A cells (Fig. 5). Given that p38 MAPK has been shown to be essential for the H-Ras-induced invasive phenotype of MCF10A cells $(38,50)$, the results obtained in this study and our previous studies indicate a key role for p38 MAPK signaling pathway in breast cell invasion.

It has been shown that the induction of MMP-13 expression in human skin fibroblasts is mediated by $\mathrm{p} 38$ MAPK (51). The p38 MAPK pathway plays a crucial role in expression of MMP-13 and invasive phenotype of transformed squamous epithelial cells (52). The p38 MAPK pathway is required for the secretion of uPA from ovarian cancer cells (53). Activation of p38 MAPK by H-Ras induces MMP-2 upregualtion $(38,39)$. This study demonstrates that the additional activation of p38 MAPK by ErbB2 resulted in upregulation of MMP-13 and uPA while the level of MMP-2 expression was not altered. These results suggest that $\mathrm{p} 38$ MAPK activation by H-Ras alone is not sufficient for the upregulation of MMP-13 and UPA which may require a stronger activity of p38 MAPK signaling by the combined action of ErbB2 and H-Ras. A possibility still remains that ErbB2 can also contribute to the activation of signaling pathway(s) other than the p38 MAPK which may lead to the upregulation of MMP-13 and UPA. Further studies need to be performed to elucidate the detailed mechanisms underlying the ErbB2-induced upregulation of MMP-13 and UPA in H-Ras-activated breast cell system.

Taken together, the present study demonstrates that ErbB2 promotes invasive and migratory abilities of H-Rasactivated human breast epithelial cells through MMP-13 and uPA. We also show that the p38 MAPK is an essential signaling molecule in the induction of MMP-13 and UPA and invasion of H-Ras MCF10A cells overexpressing ErbB2. Given that the overexpression of ErbB2 and the activating mutation of H-Ras have been often found in mammary carcinoma, the present study elucidating the molecular mechanism underlying ErbB2-induced promotion of H-Ras MCF10A cell invasion may provide invaluable information for understanding breast cancer progression and establishing therapeutic interventions for breast cancer.

\section{Acknowledgements}

This study was supported by the KOSEF NRL Program (MEST, no. ROA-2008-000-20070-0).

\section{References}

1. Bargmann L, Hung MC and Weinberg RA: The neu oncogene encodes an epidermal growth factor receptor-related protein. Nature 319: 226-230, 1986.

2. Holbro T, Civenni G and Hynes NE: The ErbB receptors and their role in cancer progression. Exp Cell Res 284: 99-110, 2003.

3. Satoh T, Endo M, Nakafuku M, Akiyama T, Yamamoto T and Kaziro Y: Accumulation of p21ras. GTP in response to stimulation with epidermal growth factor and oncogene products with tyrosine kinase activity. Proc Natl Acad Sci USA 87: 7926-7929, 1990.

4. Von Lintig FC, Dreilinger AD, Varki NM, Wallace AM, Casteel DE and Boss GR: Ras activation in human breast cancer. Breast Cancer Res Treat 62: 51-62, 2000.

5. Yarden Y: Biology of HER2 and its importance in breast cancer. Oncology 61: 1-13, 2001.

6. Denhardt DT: Oncogene-initiated aberrant signaling engenders the metastatic phenotype: synergistic transcription factor interactions are targets for cancer therapy. Crit Rev Oncog 7: 261-291, 1996. 
7. Algül H, Wagner M, Lesina $\mathrm{M}$ and Schmid RM: Overexpression of ErbB2 in the exocrine pancreas induces an inflammatory response but not increased proliferation. Int $\mathbf{J}$ Cancer 121: 1410-1416, 2007.

8. Slamon DJ, Godolphin W, Jones LA, Holt JA, Wong SG, Keith DE, Levin WJ, Stuart SO, Udove J, Ullrich A and McGuire WL: Studies of the HER-2/neu proto-oncogene in human breast and ovarian cancer. Science 244: 707-712, 1989.

9. Tan M, Yao J and Yu D: Overexpression of the c-erbB-2 gene enhanced intrinsic metastasis potential in human breast cancer cells without increasing their transformation abilities. Cancer Res 57: 1199-1205, 1997.

10. Bange EZ and Ullrich A: Molecular targets for breast cancer therapy and prevention. Nat Med 7: 548-552, 2001.

11. Anders CK, Hsu DS, Broadwater G, Acharya CR, Foekens JA, Zhang Y, Wang Y, Marcom PK, Marks JR, Febbo PG, Nevins JR, Potti A and Blackwell KL: Young age at diagnosis correlates with worse prognosis and defines a subset of breast cancers with shared patterns of gene expression. Young age at diagnosis correlates with worse prognosis and defines a subset of breast cancers with shared patterns of gene expression. J Clin Oncol 26: 324-330, 2008.

12. Kawa S, Matsushita H, Ohbayashi H, Semba K and Yamamoto T: A novel mouse monoclonal antibody targeting ErbB2 suppresses breast cancer growth. Biochem Biophys Res Commun 284: 329-333, 2009.

13. Kedrin D, Wyckoff J, Boimel PJ, Coniglio SJ, Hynes NE, Arteaga CL and Segall JE: ERBB1 and ERBB2 have distinct functions in tumor cell invasion and intravasation Clin Cancer Res 15: 3733-3739, 2009.

14. MacDougall JR and Matrisian LM: Contributions of tumor and stromal matrix metalloproteinases to tumor progression, invasion and metastasis. Cancer Metastasis Rev 14: 351-362, 1995.

15. Liotta LA and Kohn EC: Stromal therapy: the next step in ovarian cancer treatment. J Natl Cancer Inst 94: 1113-1114, 2002.

16. Deryugina EI and Quigley JP: Matrix metalloproteinases and tumor metastasis. Cancer Metastasis Rev 25: 9-34, 2006.

17. Tryggvason K, Hoyhtya M and Pyke C: Type IV collagenases in invasive tumors. Breast Cancer Res Treat 24: 209-218, 1993.

18. Sato H, Takino T, Okada Y, Cao J, Shinagawa A, Yamamoto E and Seiki MA: Matrix metalloproteinase expressed on the surface of invasive tumour cells. Nature 370: 61-65, 1994.

19. Cazorla M, Hernández L, Nadal A, Balbín M, López JM, Vizoso F, Fernández PL, Iwata K, Cardesa A, López-Otín C and Campo E: Collagenase-3 expression is associated with advanced local invasion in human squamous cell carcinomas of the larynx. J Pathol 186: 144-150, 1997.

20. Culhaci N, Metin K, Copcu E and Dikicioglu E: Elevated expression of MMP-13 and TIMP-1 in head and neck squamous cell carcinomas may reflect increased tumor invasiveness. BMC Cancer 3: 4-42, 2004.

21. Chapman HA: Plasminogen activators, integrins, and the coordinated regulation of cell adhesion and migration. Curr Opin Cell Biol 9: 714-724, 1997.

22. Andreasen PA, Kjoller L, Christensen L and Duffy MJ: The urokinase-type plasminogen activator system in cancer metastasis, a review. Int J Cancer 72: 1-22, 1997.

23. Moons L, Shi C, Ploplis V, Plow E, Haber E, Collen D and Carmeliet P: Reduced transplant arteriosclerosis in plasminogendeficient mice. J Clin Invest 102: 1788-1797, 1998.

24. Lijnen HR, van Hoef B, Lupu F, Moons L, Carmeliet P and Collen D: Function of the plasminogen/plasmin and matrix metalloproteinase systems after vascular injury in mice with targeted inactivation of fibrinolytic system genes. Arterioscler Thromb Vasc Biol 18: 1035-1045, 1998.

25. Urban P, Vuaroqueaux V, Labuhn M, Delorenzi M, Wirapati P, Wight E, Senn HJ, Benz C, Eppenberger U and EppenbergerCastori S: Increased expression of urokinase-type plasminogen activator mRNA determines adverse prognosis in ErbB2positive primary breast cancer. J Clin Oncol 24: 4245-4253, 2006.

26. Bosc DG, Goueli BS and Janknecht R: HER2/Neu-mediated activation of the ETS transcription factor ER81 and its target gene MMP-1. Oncogene 20: 6215-6224, 2001.

27. Gum R, Wang SW, Lengyel E, Yu D, Hung MC, Juarez J and Boyd D: Up-regulation of urokinase-type plasminogen activator expression by the HER2/neu proto oncogene. Anticancer Res 15: $1167-1172,1995$.
28. Ke Z, Lin H, Fan Z, Cai TQ, Kaplan RA, Ma C, Bower KA, Shi X and Luo J: MMP-2 mediates ethanol-induced invasion of mammary epithelial cells overexpressing ErbB2. Int J Cancer 119: 8-16, 2006.

29. Rocca GL, Pucci-Minafra I, Marrazzo A, Taormina P and Minafra S: Zymographic detection and clinical correlations of MMP-2 and MMP-9 in breast cancer sera. Br J Cancer 90: 1414-1421, 2004.

30. Pellikainen JM, Ropponen KM, Kataja VV, Kellokoski JK, Eskelinen MJ and Kosma VM: Expression of matrix metalloproteinase (MMP)-2 and MMP-9 in breast cancer with a special reference tovactivator protein-2, HER2, and prognosis. Clin Cancer Res 10: 7621-7628, 2004.

31. Urban P, Vuaroqueaux V, Labuhn M, Delorenzi M, Wirapati P, Wight E, Senn HJ, Benz C, Eppenberger U and EppenbergerCastori S: Increased expression of urokinase-type plasminogen activator mRNA determines adverse prognosis in ErbB2positive primary breast cancer. J Clin Oncol 24: 245-253, 2006

32. Kim IY, Yong HY, Kang KW and Moon A: Overexpression of ErbB2 induces invasion of MCF10A human breast epithelial cells via MMP-9. Cancer Lett 275: 227-233, 2009.

33. Kiaris H and Spandidos DA: Mutations of ras genes in human tumours. Int J Oncol 7: 413-421, 1995.

34. Clark GJ and Der CJ: Aberrant function of the Ras signal transduction pathway in human breast cancer. Breast Cancer Res Treat 35: 133-144, 1995.

35. Watson DM, Elton RA, Jack WJ, Dixon JM, Chetty U and Miller WR: The H-ras oncogene product $\mathrm{p} 21$ and prognosis in human breast cancer. Breast Cancer Res Treat 17: 161-169, 1991.

36. Franks LM and Teich NM: Cellular and Molecular Biology of Cancer. Oxford University Press, 1997.

37. Moon A, Kim MS, Kim TG, Kim SH, Kim HE, Chen YQ and Choi Kim HR: H-ras, but not N-ras, induces an invasive phenotype in human breast epithelial cells: a role for MMP-2 in the H-rasinduced invasive phenotype. Int J Cancer 85: 176-181, 2000.

38. Kim MS, Lee EJ, Choi Kim HR and Moon A: p38 kinase is a key signaling molecule for H-ras-induced cell motility and invasive phenotype in human breast epithelial cell. Cancer Res 63: 5454-5461, 2003

39. Song H, Ki SH, Kim SG and Moon A: Activating transcription factor 2 mediates matrix metalloproteinase-2 transcriptional activation induced by p38 in breast epithelial cells. Cancer Res 66: 10487-10496, 2006.

40. Lee JY, Han CY, Yang JW, Smith C, Kim SK, Lee EY, Kim SG and Kang KW: Induction of glutathione transferase in insulinlike growth factor type I receptor-overexpressed hepatoma cells. Mol Pharmacol 72: 1082-1093, 2007.

41. Benard V, Bohl BP and Bokoch GM: Characterization of Rac and $\mathrm{Cdc} 42$ activation in chemoattractant-stimulated human neutrophils using a novel assay for active GTPases. J Biol Chem 274: 3198-3204, 1999.

42. Moon A, Yong HY, Song JI, Cukovic D, Salagrama S, Kaplan D, Putt D, Kim H, Dombkowski A and Kim HR: Global gene expression profiling unveils S100A8/A9 as candidate markers in $\mathrm{H}$-Ras-mediated human breast epithelial cell invasion. Mol Cancer Res 6: 1544-1553, 2008.

43. Downward J: Targeting RAS signalling pathways in cancer therapy. Nat Rev Cancer 3: 11-22, 2003.

44. Tal-Or P, Erlich S, Porat-Shliom N, Goldshmit Y, Ben-Baruch G, Shaharabani E, Kloog Y and Pinkas-Kramarski R: Ligandindependent regulation of ErbB4 receptor phosphorylation by activated Ras. J Cell Biochem 98: 1482-1494, 2006.

45. Eckert LB, Repasky GA, Ulkü AS, McFall A, Zhou H, Sartor CI and Der CJ: Involvement of Ras activation in human breast cancer cell signaling, invasion, and anoikis. Cancer Res 64: 4585-4592, 2004.

46. Kruszewski W, Kowara R, Rzepko R, Warezak C, Zielinski J, Gryglewski G, Kopacz A, Jastrzebski T and Pawelczyk T: K-RAS point mutation, and amplification of c-myc and C-ERBB2 in colon adenocarcinoma. Folia Histochem Cytobiol 42: 173-179, 2004.

47. O-charoenrat P, Rhys-Evans PH, Archer DJ and Eccles SA: $\mathrm{C}$-erbB receptors in squamous cell carcinomas of the head and neck: clinical significance and correlation with matrix metalloproteinases and vascular endothelial growth factors. Oral Oncol 38: 73-80, 2002.

48. Meng S, Tripathy D, Shete S, Ashfaq R, Saboorian H, Haley B, Frenkel E, Euhus D, Leitch M, Osborne C, Clifford E, Perkins S, Beitsch P, Khan A, Morrison L, Herlyn D, Terstappen LW, Lane N, Wang J and Uhr J: uPAR and HER-2 gene status in individual breast cancer cells from blood and tissues. Proc Natl Acad Sci USA 103: 7361-17365, 2006. 
49. Zhang B, Cao X, Liu Y, Cao W, Zhang F, Zhang S, Li H, Ning L, Fu L, Niu Y, Niu R, Sun B and Hao X: Tumor-derived matrix metalloproteinase-13 (MMP-13) correlates with poor prognoses of invasive breast cancer. BMC Cancer 28:8:83, 2008.

50. Shin I, Kim S, Song H, Kim HR and Moon A: H-Ras-specific activation of Rac MKK3/6-p38 pathway: its critical role in invasion and migration of breast epithelial cells. J Biol Chem 280: 14675-14683, 2005.

51. Ravanti L, Heino J, López-Otín C and Kähäri VM: Induction of collagenase-3 (MMP-13) expression in human skin fibroblasts by three-dimensional collagen is mediated by p38 mitogenactivated protein kinase. J Biol Chem 274: 2446-2455, 1999.
52. Johansson N, Ala-aho R, Uitto V, Grénman R, Fusenig NE, López-Otín C and Kähäri VM: Expression of collagenase-3 (MMP-13) and collagenase-1 (MMP-1) by transformed keratinocytes is dependent on the activity of p38 mitogen activated protein kinase. Cell Sci 113: 227-235, 2000.

53. Estrella VC, Eder AM, Liu S, Pustilnik TB, Tabassam FH, Claret FX, Gallick GE, Mills GB and Wiener JR: Lysophosphatidic acid induction of urokinase plasminogen activator secretion requires activation of the p38MAPK pathway. Int J Oncol 31: 441-449, 2007. 